\title{
O Príncipe Feliz de Oscar Wilde
}

\author{
Edvardo Freitas
}

Lá no alto da cidade, em uma elevada coluna, ficava a estátua do Príncipe Feliz. Ele era todo decorado com finas folhas de bom ouro, e tinha como olhos duas brilhantes safiras, e um enorme rubi vermelho brilhava no cabo de sua espada.

Ele era realmente muito admirado. "Ele é tão bonito quanto um cata-vento", observou um político, sugerindo alguma sensibilidade artística; "só não é muito útil", adicionou, temendo que pudessem achá-lo pouco prático, o que realmente não era.

"Por que você não consegue ser feliz como o Príncipe Feliz?", perguntou uma mãe compreensiva ao filho que chorava à toa. "O Príncipe Feliz nem sonha chorar por coisa alguma".

"Fico feliz por ver alguém tão feliz", resmungou um homem desiludido enquanto contemplava a linda estátua.

"Ele até parece um anjo", disseram as Crianças da Caridade, quando saíam da catedral em suas brilhantes capas vermelhas e seus inocentes aventais brancos.

"Como vocês sabem?", perguntou o Professor de Matemática, "vocês nunca viram um anjo".

"Ah, nós vimos, em nossos sonhos", responderam as crianças; e o Professor de Matemática franziu o cenho e ficou muito sério, pois ele não aprovava que as crianças sonhassem. 
Uma noite voou pela cidade uma pequena Andorinha. Suas amigas haviam voado para o Egito havia seis semanas, mas ela ficara para trás, pois estava apaixonada pelo mais lindo Junco. Ela o conhecera na primavera, quando voava sobre o rio atrás de uma enorme Mariposa amarela, e ficara tão atraída por sua pequena cintura que parara para falar com ele.

"Eu posso amar você?" disse a Andorinha, que gostava de ir direto ao ponto, e o Junco fez-lhe uma pequena saudação. Então a Andorinha voou ao seu redor por horas, tocando a água com suas asas. Essa era sua corte, e durou todo o verão.

"Essa amizade é ridícula", alvoroçaram-se as outras Andorinhas; "ele não tem dinheiro, e tem muitas relações", e de fato o rio estava repleto de Juncos. Então quando veio o outono, elas todas foram embora.

Depois que elas se foram, a Andorinha se sentiu muito sozinha, e começou a cansar de seu amado. "Ele não tem conversa", ela disse, "e eu acho que ele é um namorador, porque está sempre flertando com a brisa". E com certeza, sempre que corria uma brisa, o Junco fazia as mais graciosas reverências. "Eu entendo que ele seja caseiro", ela continuou, "mas eu amo viajar, e então meu marido, conseqüentemente, também deve amar viajar".

"Você vem embora comigo?", ela disse finalmente; mas o Junco balançou a cabeça, ele era tão ligado à sua casa.

"Você está me esnobando", ela disse.

"Eu vou embora para as pirâmides. Adeus!", e partiu voando.

Todo o dia ela voou, e à noite à cidade chegou. "Onde me hospedarei?" disse ela. "Espero que a cidade tenha feito preparativos."

Então ela viu a estátua na alta coluna.

"Hospedar-me-ei aqui", ela disse; "é um ótimo lugar, com muito ar fresco". Então ela pousou entre os pés do Príncipe Feliz. 
"Tenho uma quarto dourado", ela disse suavemente para si mesma, enquanto olhava à sua volta, e se preparava para dormir; mas bem quando estava colocando sua cabeça embaixo da asa, uma enorme gota d'água caiu sobre ela. "Que coisa mais curiosa!" ela disse; "não há sequer uma única nuvem no céu, e as estrelas estão tão lindas e brilhantes, e ainda assim está chovendo. O clima no norte da Europa é mesmo terrível. O Junco gostava da chuva, mas isso era mero egoísmo dele".

Então caiu mais uma gota.

"Qual é a utilidade de uma estátua se ela não detém a chuva?", disse ela; "eu tenho que procurar uma boa chaminé", e se determinou a ir embora.

Mas antes mesmo que abrisse suas asas, caiu uma terceira gota, e ela olhou para cima, e viu - Ah! O que ela viu?

Os olhos do Príncipe Feliz estavam cheios de lágrimas, e lágrimas corriam por suas bochechas douradas. Seu rosto estava tão belo à luz do luar que a pequenina Andorinha se encheu de piedade.

"Quem é você?" disse ela.

"Eu sou o Príncipe Feliz".

"Então por que você está chorando?" perguntou a Andorinha; "você me encharcou toda".

"Quando eu estava vivo e tinha um coração humano", respondeu a estátua, "eu não sabia o que eram lágrimas, porque vivia no Palácio de Sans-Souci, aonde a tristeza não pode entrar. Durante o dia eu brincava no jardim com meus companheiros, e à noite liderava a dança no Salão. Ao redor do jardim havia um muro muito alto, mas nunca me preocupei em saber o que havia além dele, tudo à minha volta era tão lindo. Meus cortesãos me chamavam de o Príncipe Feliz, e feliz eu realmente era, se prazer for felicidade. Assim vivi, e assim morri. E agora que estou morto, me colocaram aqui em cima, tão alto que posso ver toda a feiúra 
e toda a miséria de minha cidade, e embora meu coração seja feito de chumbo, ainda assim só consigo chorar".

"O quê! Não é de ouro puro?", disse a Andorinha para si mesma. Ela era muito educada para fazer qualquer comentário pessoal em voz alta.

"Lá longe", continuou a estátua em voz baixa e musical, "lá longe em uma pequena rua, há uma casa muito pobre. Uma das janelas está aberta, e através dela posso ver uma mulher em uma mesa. Seu rosto é magro e cansado, e ela tem mãos ásperas e vermelhas, bastante machucadas pelas agulhas, pois é uma costureira. Ela está bordando flores-da-paixão em um vestido de cetim para a mais linda das damas de honra da Rainha, para que ela o use no próximo Baile da Corte. Em uma cama no canto do quarto, está deitado seu filho doente. Ele está com febre, e está pedindo laranjas. Sua mãe não tem nada além de água do rio para lhe dar. Andorinha, Andorinha, pequenina Andorinha, você pode o rubi da capa de minha espada para ela levar? Meus pés estão presos a este pedestal, e eu não me posso mover".

"Estão me esperando no Egito", disse a Andorinha. "Minhas amigas estão voando sobre o Nilo, estão correndo o rio, e falando com as enormes lotos. Logo eles dormirão no túmulo do grande Rei. $O$ próprio Rei está lá em seu ornamentado caixão. Ele está envolto em linho amarelo, e embalsamado com deliciosas fragâncias. Ao redor de seu pescoço há uma corrente de verde-clara jade, e suas mãos são feito folhas secas".

"Andorinha, Andorinha, pequenina Andorinha", disse o Príncipe, "você não fica comigo mais uma noite, e leva minha mensagem? O garotinho está com tanta sede, e a mãe tão triste".

"Eu não gosto de garotos", respondeu a Andorinha. "No verão passado, quando eu estava ficando no rio, havia dois garotos malvados, os filhos dos Miller, que ficavam sempre jogando 
pedras em mim. Eles nunca me acertaram, é claro; nós, andorinhas, voamos bem demais para isso, e, além do mais, eu venho de uma família famosa por sua agilidade; mas, ainda assim, era um sinal de desrespeito".

Mas o Príncipe Feliz ficou tão triste que a pequenina Andorinha teve pena. "Está muito frio aqui", ela disse, "mas eu ficarei mais uma noite, e serei sua mensageira".

"Muito obrigado, pequenina Andorinha", disse o Príncipe.

Então a Andorinha pegou o rubi da espada do Príncipe, e voou com ele em seu bico por sobre os telhados da cidade.

Ela passou pela torre da catedral, onde estavam esculpidos anjos de mármore branco. Passou pelo palácio e ouviu o som da dança. Uma bela garota saiu na sacada com seu namorado. "Como são lindas as estrelas", ele disse para ela, "e como é maravilhoso o poder do amor!"

"Espero que meu vestido esteja pronto para o baile", ela respondeu, "eu mandei bordar flores-da-paixão nele; mas as costureiras são tão preguiçosas".

Ela passou por sobre o rio, e viu as lanternas penduradas nos mastros dos navios. Ele passou por um bairro rico, e viu os velhos ricos barganhando uns com os outros, e pesando seus dinheiros em balanças de cobre. Finalmente ela chegou à pobre casa e olhou para dentro. $O$ garoto estava tossindo febrilmente em sua cama, e sua mãe havia adormecido, estava tão cansada. Para dentro ela voou, e sobre a mesa, ao lado do dedal da muIher, o rubi deixou. Então voou gentilmente ao redor da cama, abanando a fronte do garoto com suas asas. "Como está fresquinho", disse o garoto, "devo estar melhorando", e mergulhou em um delicioso cochilo.

Então a Andorinha voou de volta para o Príncipe Feliz, e lhe contou o que fizera. "É curioso", ela observou, "mas eu estou com calor agora, embora esteja tão frio". 
"É porque você fez uma boa ação", disse o Príncipe. E a pequenina Andorinha começou a pensar, e depois adormeceu. Pensar sempre a fazia adormecer.

Quando o dia raiou, ela voou até o rio e tomou um banho. "Que fenômeno admirável", disse o Professor de Ornitologia, quando passava pela ponte. "Uma Andorinha no inverno!" E ele escreveu um longo artigo sobre ela no jornal local. Todo mundo comentou o artigo, que era tão cheio de palavras que eles não conseguiam entender.

"Hoje à noite vou para o Egito", disse a Andorinha, muito animada com tal perspectiva. Ela visitou todos os monumentos públicos, e sentou por um bom tempo na torre da igreja. E aonde quer que ela fosse, os Pardais gorjeavam, e diziam uns aos outros, "Que forasteira distinta!", e a apreciavam muitíssimo.

Quando a lua levantou, ela voou de volta até o Príncipe Feliz. "Você tem alguma incumbência para o Egito?" ela disse; "eu já estou partindo".

"Andorinha, Andorinha, pequenina Andorinha", disse o Príncipe, "você não fica comigo mais uma noite?"

"Estão me esperando no Egito", respondeu a Andorinha. "Amanhã meus amigos voarão até a Segunda Catarata. $\bigcirc$ hipopótamo se deita lá entre os juncos, e em um grande trono de granito se senta o Deus Menon. Durante toda a noite ele observa as estrelas, e quando a estrela da manhã brilha, ele dá um grito de alegria, e depois silencia. À noite os leões amarelos descem até a beira da água para bebê-la. Eles têm olhos verdes como berilos, e rugem mais alto que a catarata".

"Andorinha, Andorinha, pequenina Andorinha", disse o Príncipe, "lá longe, muito longe, do outro lado da cidade, vejo um jovem em um sótão. Ele está debruçado em uma mesa cheia de papéis, e em um vaso a seu lado há um buquê de violetas murchas. Seu cabelo é castanho e crespo, e seus lábios são verme- 
Ihos como a maçã, e ele tem olhos grandes e sonhadores. Ele está tentando terminar uma peça para o Diretor do Teatro, mas está com muito frio para seguir escrevendo. Não há fogo na lareira, e ele está debilitado pela fome".

"Eu esperarei com você mais uma noite", disse a Andorinha, que de fato tinha um ótimo coração. "Eu devo levar a ele outro rubi?"

"Ah! Já não mais tenho rubis", disse o Príncipe; "meus olhos são tudo o que me resta. Eles são de raras safiras, trazidas da Índia há mil anos. Arranque um deles e leve para ele. Ele o venderá para um joalheiro, e comprará comida e lenha para o fogo, e terminará sua peça".

"Querido Príncipe", disse a Andorinha, "eu não posso fazer isso"; e pôs-se a chorar.

"Andorinha, Andorinha, pequenina Andorinha", disse o Príncipe, "faça o que estou mandando".

Então a Andorinha arrancou o olho do Príncipe, e voou até o sótão do garoto. Foi bastante fácil entrar lá, pois havia um buraco no telhado. Pelo buraco ela voou, e no quarto entrou. $\bigcirc$ jovem estava com a cabeça enterrada entre as mãos, e não ouviu o bater das asas do pássaro, e quando ele olhou para cima, encontrou a linda safira deitada sobre as murchas violetas.

"Estou começando a ser apreciado", ele disse; "isto é de algum grande admirador. Agora posso terminar minha peça", e ficou muito feliz.

No outro dia a Andorinha voou até o porto. Ele sentou no mastro de um enorme navio e assistiu aos marinheiros retirarem, com enormes cordas, grandes caixas de dentro dos porões. "Levanta", eles gritavam a cada caixa que subia. "Estou indo para o Egito!" gritou a Andorinha, mas ninguém se importou, e quando a lua levantou, ela voou de volta para o Príncipe Feliz.

"Eu vim dizer adeus", disse. 
"Andorinha, Andorinha, pequenina Andorinha", disse o Príncipe, "você não fica comigo mais uma noite?"

"É inverno", respondeu a Andorinha, "e a fria neve logo estará aqui. No Egito o sol está quente nas verdes palmeiras, e os crocodilos deitam na lama e olham preguiçosos por entre as palmeiras. Meus companheiros estão construindo um ninho no Templo de Baalbec, e os pombos cor-de-rosa e brancos os estão observando, e cantando uns para os outros. Querido Príncipe, eu tenho que deixá-lo, mas nunca o esquecerei, e na próxima primavera the trarei duas lindas jóias, para colocar no lugar das que doou. O rubi há de ser mais vermelho do que uma rosa, e a safira há de ser mais azul que o imenso oceano".

"Na praça lá em baixo", disse o Príncipe Feliz, "está uma garota que vende fósforos. Ela deixou seus fósforos caírem na sarjeta, e eles estão todos estragados. $O$ pai a surrará se não levar algum dinheiro para casa, e ela está chorando. Ela está sem sapatos nem meias, e sua cabecinha está descoberta. Arranque meu outro olho e dê para ela, e o pai não the há de bater".

"Eu ficarei com você por mais uma noite", disse a Andorinha, "mas não posso arrancar-lhe o outro olho. Você ficaria completamente cego".

"Andorinha, Andorinha, pequenina Andorinha", disse o Príncipe, "faça como the mando".

Então ela arrancou o outro olho do Príncipe, e voou cidade abaixo com ele. Ela voou perto da garotinha, e soltou a jóia bem na palma de sua mão. "Que lindo pedaço de vidro", disse a pequena garotinha; e correu para casa, rindo bastante.

Então a Andorinha voltou para o Príncipe. "Você está cego agora", ela disse, "então eu ficarei sempre com você".

"Não, pequenina Andorinha", disse o pobre Príncipe, "você deve ir para o Egito". 
"Eu ficarei sempre com você", disse a Andorinha, e ela dormiu nos pés do Príncipe.

Todo o dia seguinte ela ficou no ombro do Príncipe, e contou-Ihe histórias de quando estivera em terras estranhas. ContouIhe das íbis vermelhas, que ficam em longas filas nas ribanceiras do Nilo, e pegam peixes dourados em seus bicos; e da Esfinge, que é tão velha quanto o próprio mundo, e vive no deserto, e sabe tudo o que há para saber; e dos mercadores, que caminham lentamente ao lado de seus camelos, e carregam rosários de âmbar em suas mãos; e do Rei das Montanhas da Lua, que é tão negro quanto o ébano, e venera um enorme cristal; e da grande cobra verde que dorme em uma palmeira, e tem vinte sacerdotes para alimentá-la com bolos de mel; e sobre os pigmeus que velejam sobre um grande lago em enormes folhas planas, e estão sempre em guerra com as borboletas.

"Minha querida e pequenina Andorinha", disse o Príncipe, "Você me conta coisas fantásticas, mas o mais fantástico de tudo é o sofrimento dos homens e mulheres. Não há mistério maior do que a Miséria. Voe sobre minha cidade, pequenina Andorinha, e me conte o que lá vir".

Então a Andorinha voou sobre a grande cidade, e viu os ricos fazendo festas em suas lindas casas, enquanto os mendigos sentavam nos portões. Ela voou por ruelas escuras, e viu as faces das crianças famintas observando apáticas as ruas sombrias. Sob o arco de uma ponte viu dois garotinhos deitados, abraçados um ao outro para espantar o frio imenso. "Que fome terrível!" eles disseram. "Vocês não podem deitar aqui", disse o Vigia, e eles saíram caminhando pela chuva.

Então ela voltou e contou ao Príncipe o que tinha visto.

"Eu estou coberto de bom ouro", disse o Príncipe, "você deve tirá-lo, folha por folha, e dá-lo para os pobres; os vivos pensam que o ouro pode fazê-los felizes". 
Folha após folha do bom ouro a Andorinha tirou, até o Príncipe Feliz ficar muito feio e cinzento. Folha após folha do bom ouro ela levou até os pobres, e as faces das crianças ficaram mais coradas, e elas riram e brincaram nas ruas. "Nós temos pão agora!", elas gritavam.

Então veio a neve, e após a neve veio a geada. As ruas pareciam feitas de prata, de tão brilhantes e resplandecentes; longos pingentes de gelo, feito adagas de cristal, pendiam das abas das casas, e todo mundo andava vestido com peles, e os dois garotinhos usavam gorros vermelhos e patinavam no gelo.

A pobre e pequenina Andorinha ficou cada vez com mais frio, mas ela não deixaria o Príncipe, pois o amava demais. Ela pegou migalhas de pão na porta da padaria, quando o padeiro não estava olhando, e tentou se manter aquecida batendo suas asinhas.

Mas finalmente entendeu que iria morrer. Ela só teve força para voar mais uma vez até o ombro do Príncipe. "Adeus, Príncipe querido", ela murmurou, "você me deixa beijar sua mão?"

"Estou feliz que finalmente vá para o Egito, pequena Andorinha", disse o Príncipe, "você ficou demais por aqui; mas você deve beijar-me nos lábios, porque eu amo você".

"Não é para o Egito que vou", disse a Andorinha. "Vou para a Casa da Morte. A Morte é a irmã do Sono, não é?"

E ela beijou o Príncipe Feliz nos lábios, e caiu morta a seus pés.

Naquele momento um curioso estalo soou dentro da estátua, assim como se algo se tivesse quebrado. $O$ fato é que o coração de chumbo se tinha partido em dois. Era com certeza um frio terrível.

Na manhã seguinte, cedo o Prefeito estava caminhando na praça ao lado dos vereadores. Quando passaram pela coluna, ele olhou para cima para a estátua: "Nossa! Como o Príncipe feliz está maltrapilho", ele disse. 
"Realmente, que maltrapilho", disseram os vereadores, que sempre concordavam com o Prefeito; e eles subiram para olhá-lo.

"O rubi caiu de sua espada, seus olhos se foram, e ele não é mais de ouro", disse o Prefeito; "na verdade, ele está pouco melhor do que um mendigo!"

"Pouco melhor do que um mendigo", disseram os vereadores.

"E há até um pássaro morto em seus pés!" continuou o Prefeito.

"Nós temos que baixar um decreto que proíba os pássaros de morrerem aqui". E o Secretário da Câmara anotou a sugestão.

Então eles derrubaram a estátua do Príncipe Feliz. "Como ele não é mais bonito, não tem mais utilidade", disse o Professor de Arte na Universidade.

Então eles derreteram a estátua em uma fornalha, e o Prefeito convocou uma reunião na Corporação para se decidir o que se faria com o metal. "Nós temos que fazer outra estátua, é claro", disse ele, "e há de ser uma estátua de mim mesmo".

"De mim", disseram todos os vereadores, e eles discutiram e argumentaram. Da última vez que ouvi falar neles, ainda estavam discutindo.

"Que coisa mais estranha", disse o supervisor dos trabalhadores na fundição. "Este coração de chumbo partido não derrete na fornalha. Temos que jogá-lo fora". Então eles o jogaram no monte de poeira em que jazia morta a Andorinha.

"Traga-me as duas coisas mais preciosas da cidade", disse Deus para um de Seus Anjos, e o Anjo trouxe o coração partido e o pássaro morto para Ele.

"Você escolheu acertadamente", disse Deus, " pois no meu jardim do Paraíso, o pequeno pássaro para todo o sempre cantará, e em minha cidade dourada, o Príncipe Feliz louvar-me-á. 